Identity Development in Cultural Context: The Role of Deviating from Master Narratives

\author{
Kate C. McLean ${ }^{1}$ \\ Jennifer P. Lilgendahl ${ }^{2}$ \\ Chelsea Fordham ${ }^{1}$ \\ Elizabeth Alpert ${ }^{2}$ \\ Emma Marsden ${ }^{2}$ \\ Kathryn Szymanowski ${ }^{2}$ \\ Dan P. McAdams ${ }^{3}$
}

${ }^{1}$ Western Washington University

${ }^{2}$ Haverford College

${ }^{3}$ Northwestern University

Corresponding Author:

Kate McLean

Western Washington University

Department of Psychology, MS 9172

516 High Street

Bellingham, WA 98225

Kate.McLean@wwu.edu

Acknowledgements.

We thank the following colleague who provided critiques of earlier versions of this paper: Moin Syed, Adriana Manago, and Lucy Purgason. We also thank the narrative lab at Western Washington University for assistance with data collection of Study 2, and coding of all studies. Finally, we thank Jon Adler and two anonymous reviewers for very thoughtful comments on a prior version of this manuscript. Data collection for Study 3 was supported by a grant to Dan P. McAdams to fund the Foley Center for the Study of Lives at Northwestern University. Special thanks go out to Gina Logan and her team for collecting and organizing those data. Finally, we thank our participants for sharing their stories.

McLean, K. C., Lilgendahl, J. P., Fordham, C., Alpert, L., Marsden, E., \& Szymanowski, K., \& McAdams, D. P. (2017). Master Identity Development in Cultural Context: The Role of Deviating from Master Narratives. Journal of Personality, 65, $1-21$. 


\begin{abstract}
Objective: The great majority of research on identity and personality development has focused on individual processes of development, to the relative neglect of the cultural context of development. We employ a recently articulated framework for the examination of identity development in context, centered on the construct of master narratives, or culturally shared stories.

Method: Across three studies we asked emerging and mid-life adults $(n=512)$ to narrate personal experiences of deviations from these master narratives.

Results: Across three quantitative studies we show that 1) those who elaborated their deviation experiences were more likely to be in structurally marginalized positions in society (e.g., ethnic or sexual minorities); 2) those who elaborated an empowering alternative to the master narrative were more likely to be engaged in identity processes; and 3) master narratives maintain their rigidity by the frequency of their use. In qualitative analyses, we illustrate the rigidity of master narratives, as well as the degree to which they take shape in social and group experiences. Conclusions: These studies emphasize the importance of cultural context in considering personality and identity development.
\end{abstract}

Key words: narrative identity, master narratives, culture, identity development 


\section{Identity Development in Cultural Context: The Role of Deviating from Master Narratives}

My whole life I always felt there was something slightly different about me regarding my sexual orientation. I grew up in a very hetero normative household and followed what I was taught. I am very masculine and never could accept the possibility of being gay until I got married to my girlfriend that I was with for about five years. I now don't place a label on my sexuality but am interested in dating men. This is common but definitely diverges from the hetero normative story that is set out for me to follow. I struggled with a lot of depression for a few years but after accepting myself I have never felt better.

In the narrative above we hear a part of one person's life story, concerning his family of origin, relationship experiences, sexuality, and mental health. In telling this story, however, this person does not only tell us about his experiences, but he also tells about the culture in which he is developing. Through this personal story we gain access to a cultural master narrative concerning what the expected, and unexpected, events are in a life course, particularly pertaining to sexuality and relationships. The aim of this paper was to use stories such as these to test initial ideas from a framework concerning the use of cultural master narratives for understanding personal identity development.

Identity development is a psychosocial task that is relevant across the adult lifespan, involves constructing a sense of personal continuity across time and context, and is a critical marker of healthy psychosocial development (Erikson, 1968). Though prior research has established a strong understanding of critical processes important to the task of constructing an identity, this body of research has engaged in a relative neglect of an important component of Erikson's original theory: cultural context. That is, the focus of past research on identity development has been overwhelmingly on the individual, and far less on the cultural context in which the individual is developing. Seeking to remedy some of these issues, we took a cultural approach to the examination of identity development using a recently proposed Master Narrative Framework designed to empirically articulate the relation between individuals and their cultural 
context (McLean \& Syed, 2015). The aim of the current study was an initial empirical investigation of this framework to test some of the premises put forth by McLean \& Syed (2015). We offer this preliminary investigation using two distinct university samples and one community mid-life sample. We used both quantitative and qualitative approaches, across four studies, to examine personal narratives of deviations from cultural master narratives, as well as the role that the construction of alternative narratives plays in identity development. In doing so we can better see how culture can both support and constrain identity development, and the role that individuals play in the dynamics of creating and sustaining culture.

\section{Identity Development: Theoretical Foundations and the Focus on the Individual}

Identity development is viewed as a lifelong task, as are all Eriksonian stages (Erikson, 1959; see also Syed \& McLean, in press), but it demands special attention in adolescence and emerging adulthood (Arnett, 2000; Erikson, 1968; McAdams, 2015; McLean \& Syed, 2014). The task of identity development involves constructing a sense of personal continuity between past and present and future, across contexts, and between self and culture (Pasupathi, Mansour, \& Brubaker, 2007; Syed \& McLean, 2015); this is no easy task. It takes sophisticated cognitive effort to find connections across these areas, particularly when they are in conflict; if one feels the conflict, one is likely to be motivated to reconcile it (Habermas \& Köber, 2015; Harter \& Monsour, 1992). Finally, it takes cultural and social presses; others may insist that one engage this task so that the self is known to others, and so that the self is able to engage fully in personal and cultural relationships, to be a citizen of one's community (Erikson, 1968; McLean, 2015). Thus, while adolescence is a time when individuals begin to engage with these ideas, particularly when they think about how they are similar to or different from childhood identifications (Erikson, 1968), emerging adulthood, at least in industrialized and western societies (Arnett, 
2000), is when all three of these presses - cognitive, personal, and sociocultural - come together to make this period of the lifespan ripe for identity work (see also Habermas \& Reese, 2015).

As mentioned above, the study of identity development has traditionally occurred relatively devoid of cultural context. Part of this is related to a strong emphasis on the examination of identity processes. For example, in the identity status literature the focus has been on process of exploration and commitment (Marcia, 1966), and their more recent iterations (see Crocetti \& Meeus, 2015). Within the narrative identity literature, autobiographical reasoning has been the focus of identity development (Habermas \& Bluck, 2000; Pasupathi et al., 2007). In both of these literatures greater depth of processing (i.e., high exploration or reasoning) signals engagement with the process of understanding oneself. Further, the quietening of this processing is also important - one does not want to stay in the state of exploration, which brings with it indefinite uncertainty. This can occur by establishing commitments, within the status approach, or by achieving some form of narrative resolution. Although there is a wealth of important and meaningful research conducted under the umbrella of these identity processes, the focus is primarily decontextualized, with little attention paid to the contexts in which they are engaged in these processes. Exceptions include the examination of families (e.g., Fivush, Marin, Williams, \& Bohanek, 2009; Grotevant \& Cooper, 1985; McLean, 2015; Zaman \& Fivush, 2011), and to some extent peers (e.g., Jennings, Pasupathi, \& McLean, 2013; McLean \& Jennings, 2012; Pasupathi \& Hoyt, 2009; Ragelienė, 2016) as proximal contexts of identity development. Yet, there is a relative lack of empirical attention to the distal cultural context within psychology. Part of this lack of attention has been the challenge of defining culture and the individual on the same metric; that is, when two constructs are operationalized in very different ways, it becomes hard to examine relations 
between them with any specificity (McLean \& Syed, 2015). One consequence of this has been that culture has often been defined in static ways (e.g., as an independent variable), and dynamics are examined primarily within the person (McLean \& Syed, 2015).

We took a narrative approach as narrative can be viewed both as a mechanism for defining culture, but also how cultural meanings are made and instantiated in the lives of people. In this way, culture is not simply 'out there,' but is internalized in individual identities. The opening example provides a vivid example of this idea, as the narrator explicitly acknowledges how cultural expectations of sexuality and romantic relationships shape his understanding of himself and the narration of his story. Thus, culture not only informs personality and identity broadly (e.g., Benet-Martinez, 2012; Thorne, 2000; 2004; Thorne \& Nam, 2007), but also inhabits individuals' identities and personalities (McAdams \& Pals, 2006).

Our aim was to make an initial test of some of the propositions from a recently proposed framework designed to articulate the dynamics of identity development between individuals and their cultural context. We see this work as having the potential to advance personality psychology in important ways. Much work over the past few decades has examined culture and personality non-developmentally, by examining cross-cultural similarities and differences in traits, for example. (e.g., McCrae \& Costa, 1997). In contrast, our aim is consistent with a different, and less dominant, strand of theory and research in personality that considers the role of cultural context in understanding personality development, such as the pioneering work by Helson (e.g., Helson, Mitchel, \& Moan, 1984) and Neugarten (e.g., 1974) that emphasized the role of socio-historical context in understanding personality development. More recently, theoretical work McAdams (2006) and Hammack (2008) have revived this developmental perspective on culture and personality through the lens of narrative, which is the most 
contextualized of the levels of personality (McAdams, 2015; McAdams \& Olson, 2010). As we articulate below, our methodological approach offers a novel way to understand individual differences in how individuals engage with culture as they narrate their life stories, an inherently developmental task. Thus, narratives provide an opportune place to examine the role of cultural affordances and constraints on personality development (see also Syed, under review).

\section{The Master Narrative Framework}

Cultural theorists conceive of culture as a dynamic system (Bronfenbrenner, 1979; Rogoff, 2003; Vygotsky, 1978), but the empirical articulation of culture often comes in the form of an invariant independent variable that 'effects' individuals (e.g., Stephens, Markus, \& Freyberg, 2012). Thus, the dynamics of culture can be easily lost, and the roles that individuals play in constructing, maintaining, and potentially changing cultures can also be lost (cf., Hammack 2011). The recently proposed master narrative framework seeks to address some of these issues (McLean \& Syed, 2015; see also Hammack, 2008), and also emphasizes the critical role that power and oppression play in identity development (see also Galliher, McLean, \& Syed, in press), particularly as identities are constrained by the cultures in which they are developing. Master narratives are culturally shared stories that provide frameworks within which individuals can locate and story their own experiences. Master narratives will be culturally specific, but McLean and Syed (2015) argued that they share several principles. These principles are the ubiquity of master narratives - they must be known by the majority; utility - they must serve the purpose of defining the acceptable, valued frameworks for defining the self; invisibility - they are often internalized through unconscious processes so that many are unaware that they are conforming to cultural expectations in defining themselves; rigidity - they hold structural power in society and are difficult to change; and compulsory nature - those whose personal 
narratives do not align with these master narratives are telling stories that are less valued, less 'good,' and are in a more marginalized position in society.

Although master narratives are defined as story structures, they are viewed as enduring parts of the structure of society. For example, the American 'story' about marriage is one that is sanctified in the legal architecture of the rights afforded Americans (and appears in the narrative that opens this paper as a step in the hetero-normative story). Therefore, those who do not conform to these narratives, may be in positions of structural marginalization. Broadly, this marginalization can include being in poverty, female, or of ethnic or sexual minority or immigrant status. Of course, there are ways to deviate that are not based on ascribed social identities or biological status (e.g., choosing not to marry), but the point is that deviation puts one in a position of being marginalized from the valued structures of society (see also Warner, 2008).

McLean and Syed (2015) further defined master narratives as including three types: episodic (e.g., 9/11), structural (e.g., redemption), and biographical - the latter of which is the focus of the present studies. Biographical master narratives concern the framework for how a life should unfold (see also Arnett, in press; Bernsten \& Rubin, 2004; Habermas, 2007). This can be conceptualized as both the types of events that should occur in a life in a given culture (e.g., graduation from school, marriage), as well as the expected timing of events (e.g., marriage before childbearing). As articulated above, those whose personal narratives align with the master narrative are constructing identities that are culturally accepted and valued. Those whose personal narratives do not align are deviating from cultural expectations, and are more likely to be marginalized and oppressed (Fivush, 2004; 2010). Interestingly, there is a constraint on identity processes in both cases, but it may be more visible in the case of deviation. That is, those who align may feel as if they have chosen their life course, even as they may unwittingly 
follow the master narrative in lock step (Fivush, 2010). Those who deviate are more aware of the master narrative in part due to the social sanctions that come with deviation (see McLean, Shucard, \& Syed, 2016). Thus, it appears that an efficient way to understand the negotiation between personal and master narratives is to examine deviations from master narratives, which we do in the present set of studies.

The framework proposed by McLean and Syed (2015) includes the sample situations above - those whose narratives align with the master narrative, and those who do not representing the concept of personal and master narratives. But there is another critical construct to this framework - the alternative narrative. The theoretical proposition is that those who deviate from the master narrative are tasked with finding or constructing an alternative narrative. That is, part of the identity development project is to understand one's own life in relation to the larger group (Erikson, 1968). When one does not fit in with the larger group, then the identity work is to explain that deviation. This task may be successfully done through finding an alternative narrative that belongs to another (usually smaller, or sub-) group. For example, for those who do not follow the heterosexual life course, the 'coming out story' may serve as an alternative narrative told by a group to whom one can belong.

Building on the idea of deviation, and departing from much of the work that has emphasized the individual's role in agentically and autonomously constructing an identity, McLean and Syed (2015) argued that societal structures constrain the possibilities for identity development, putting an emphasis on power and personal agency that is relatively novel to the study of identity development (cf., Hammack, 2011). This constraint is most notable and problematic for those who are in marginalized positions; the work of defining the self is much 
more challenging for those whose lives do not conform. Indeed, aligning with alternative narratives is associated with greater engagement in identity processes (McLean et al., 2016).

We took a specific approach to agency and the alternative narrative in this study. As our intention was to examine personal identity development, we operationalized the fullest form of alternative narrative engagement as involving elaboration (one must be able to elaborate an alternative in order for it to contribute to identity), and encompassing some sense of felt agency or empowerment (see Toolis \& Hammack, 2015). That is, for an alternative narrative to 'work' to establish a coherent sense of self it may need to be developed in a way that provides a person with a sense of agency. However, this does not discount the actual agency that may still be a barrier to identity development, and which is seen in structural barriers (e.g., laws concerning parenthood for gay individuals). We return to this issue in the discussion.

Alternative narratives are not only important as a framework for those who are marginalized; they may also play a role in cultural change. For example, if enough people begin to use an alternative narrative it may subsume the master narrative, as we are beginning to see with narratives about sexuality in some countries where there have been recent and rapid attitudinal and legal changes. Here we can see how the individual can play a role in the dynamics of a culture, and this felt agency may be an important part of empowering the individual to push cultural change. However, cultural change is not such a simple story. McLean et al. (2016) found that referencing alternative narratives was both rare and challenging in conversational contexts, with participants desiring common ground rather than risking the divulgence of less common and accepted narratives. In sum, those who are engaged with alternative narratives are doing more identity work, but changing master narratives may be made challenging by the difficulty of 
sharing those personal stories that challenge the status quo - one explanation for the rigidity of master narratives.

\section{Present Studies}

Prior work has examined master and alternative narratives about specific content areas of identity (e.g., gender; McLean et al., 2016) or in full life stories (Hammack, 2011). A novel approach that, to our knowledge, has not been used before is to ask participants directly about their deviations from master narratives to better understand the master narratives themselves, as well as how alternative narratives are constructed. We address three specific proposals put forth by McLean and Syed (2015), and we also examine the role that gender and ethnicity play in all studies, as well as SES (Study 3), and sexuality (Study 2) across three samples - two samples of college-going emerging adults at very different institutions, and one mid-life sample. Our intention in Study 1 was to determine if the deviation prompt we had developed worked, and to test our initial hypotheses. In Study 2, we broadened our sample, and aimed to replicate our findings from Study 1. Study 3 is an on-going longitudinal study, and was not designed to assess master narratives. However, we were able to insert the prompt into one of the assessments, which allows a test of replication in a very different sample. Our hypotheses follow.

First, the 'compulsory nature' of master narratives emphasizes that they are a part of the power structure of a given society. Thus, we expected that those in more structurally marginalized positions would be more likely to report experiences of deviation. Second, McLean and Syed argued that one reason for the rigidity of master narratives is that in elaborating the alternative narrative one must also reference the master narrative, giving it more 'airtime.' Thus, we examined whether one can elaborate the alternative narrative without referencing the master narrative. The third proposal is that constructing an alternative narrative takes more identity 
work, and there is some extant data to support that in the context gender (McLean et al., 2016). Therefore, we expected that those who elaborate an alternative narrative should also show more identity processing, or narrative meaning-making, about their experiences.

After addressing these three propositions, we took on recent calls to examine the content of identity (Galliher et al., in press; Syed, in press). In Study 4, using a qualitative analysis, we examined the content of the narratives from those whose deviation put them in more marginalized positions in society, and who elaborated an alternative narrative. The goal here was an initial investigation into the ways in which alternative narratives form in relation to master narratives with the aim of theory-building on these concepts.

Finally, we note that we have three quite diverse samples, with different 'cultures' inherent within them. The first two samples are college students, but at quite different institutions. The participants in Study 1 come from an elite, small, private liberal arts college on the East Coast (though students come from all over the country, as well as international locales). The 'culture' of this campus centers on heightened intellectualism, community, and a commitment to social justice. The second study contains participants from a mid-sized, public university in the Pacific Northwest. The 'culture' of this institution is varied, given its size, but it certainly houses a west-coast, and relatively liberal, reputation. The final sample is a mid-life sample of adults in an urban mid-west center. This sample was recruited with the intention of capturing the diversity of the area, and it is hard to capture the 'culture' of this sample, as they do not share an institutional affiliation. Given these distinctions, we argue that similarities across samples might be evidence of broader generalizability.

\section{Study 1: Methods}

\section{Participants}


Participants were 78 undergraduate students at a small, elite, liberal arts college in the eastern United States. Seventy-two percent were females $(n=56)$, and 63\% were White $(n=$ 49), 17\% Asian $(n=13), 9 \%$ Black $(n=7), 8 \%$ Latino $((n=6), 3 \%$ Other $(n=2)$. Mean age was $19.64(S D=1.39$, range $=17-22)$.

\section{Procedure}

Participants were recruited from Psychology 100 courses or via advertising on campus. Students in Psychology 100 were compensated with course credit, and others were paid \$10. Participants came into the lab and were seated at a computer in a private room where they completed an online survey via Qualtrics. The survey contained basic demographic questions, narrative prompts about a master narrative deviation experience and an experience of sharing the deviation experience with others (not used in these analyses), and a series of follow-up ratings about the deviation reported in the narrative. Participants also completed measures of personality and well-being which were not included in the current analyses.

Narrative Prompt and Coding

The following narrative prompt was designed for the current study in order to engage participants with the question of master narrative deviation in their lives:

We all have our own personal life story made up of our experiences and interpretations of those experiences. Sometimes stories from our lives, or aspects of our lives, don't completely match the storyline that others (society, culture, family, friends, etc.) expect us to have, or what is considered appropriate, normal, or accepted. Have you ever felt that your story diverged from what was considered to be normal, expected, or accepted? Please describe it in the space provided below, including how it made you feel, and its significance to you (if any). This could be something that was a discrete event, something more general about yourself or your life, or anything in between.

Responses to this prompt were reliably coded for the qualities described below (see Syed \& Nelson, 2015). See Table 1 for illustrative examples. 
Master Narrative Elaboration. This was captured on a four-point scale. A one indicated no reference to a master narrative, or a culturally dominant storyline. A two included minimal or suggestive reference to a master narrative. A three included a clear reference to a master narrative, but which was only somewhat developed. A four indicating a detailed and welldeveloped description of a master narrative.

Alternative Narrative Elaboration. As with the rating of master narrative, a rating of 1 indicates that an alternative narrative is not present at all (e.g., meaning there is a description of an event, with no larger context), and a rating of 4 indicates that a clear, coherent and elaborated alternative narrative was reported. In addition to level of elaboration, the degree to which one experienced some agency in the story was also considered. A well-developed alternative narrative is expected to be empowering in provide a person with a sense of agency in countering the master narrative. Thus, individuals could only receive the highest score if the alternative narrative was both elaborated and agentic.

Meaning-making. Meaning-making is coded when the narrator links past experiences to some aspect of the self that transcends the specifics of the situation and is a lasting part of oneself or one's way of thinking (McLean \& Pratt, 2006). Meaning-making may be positive or negative. Coders rated each narrative for positive and negative meaning making, with a one indicating no meaning, a two indicating minimal positive/negative meaning, a three indicating clearly present but vague or unelaborated positive/negative meaning, and a four indicating that positive/negative meaning was clearly present, central, and elaborated.

Marginalization. This code was developed for the purposes of these studies and was intended to capture the degree to which one holds a structurally marginalized place in society. Upon reading the narratives we saw that there were variations on this idea of marginalization, not 
all consistent with the original theorizing about marginalization as a part of structural barriers. Thus, we developed a coding system to capture this variety. A zero was given to those who report a deviation about being different, but not in terms of structural power (e.g., different interests, personality). Those who reported a deviation that had some time component to them, meaning that they had not (or would not) always exist (e.g., divorce, job loss, mental illness), received a code of one. For those whose narratives were based on relatively "immutable" characteristics of the person (e.g., race, gender), were coded as two.

\section{Establishing Reliability}

The coding of master and alternative narrative elaboration and positive and negative meaning was completed by three coders (the last three authors), for the full set of narratives. Intraclass correlations for each pairing of the three coders ranged from $.61-.74$ for master narrative elaboration, $.72-.81$ for alternative narrative elaboration, $.75-.82$ for positive meaning-making, and $.65^{1}$ for negative meaning-making. Ratings were averaged to create a final score for each participant. The coding for marginalization was completed by the first and third author, and reliability was acceptable (kappa $=.77, n=40)$.

\section{Study 1: Results}

For our categorical analyses, we used chi-square statistics. We used Cramer's v to determine effect sizes, and adjusted standardized residuals (ASRs) to determine the location of differences in cells. Whereas a statistically significant chi-square statistic indicates global nonindependence in the contingency table, the ASR allows researchers to locate the source of the non-independence within individual cells, targeting the degree of discrepancy between observed and expected values for an individual cell. The ASR is a standardized metric, and can be

\footnotetext{
${ }^{1}$ One coder was quite divergent from the other two, so this coder was dropped for the negative meaning-making final score; the reported icc represents agreement between the other two coders.
} 
interpreted like a z-score. Descriptives of the main variables can be found in Table 2. Are Master Narrative Deviations more elaborated for those who are in more marginalized positions in society?

All participants answered the narrative prompt, meaning that all participants felt that they had deviated from the master narrative in some way. However, $62 \%$ participants reported deviation narratives that were not about structural inequality (code $=0), 23 \%$ reported a deviation about more transitional deviations (code $=1$ ), and only $15 \%$ reported a narrative in which the deviation was about being in a position of structural inequality, the most marginalized status. There was no association between the type of marginalization expressed in the narrative and meaning or alternative narrative elaboration (all $F$ 's $<2.37$ ). There was a marginal finding for master narrative development, $F(2,62)=2.41$, partial $\eta^{2}=.07, p<.10$, suggesting that narratives about being more marginalized were associated with greater elaboration of the master narrative, though post-hoc tests were not significant.

In terms of demographics, there were no gender differences for type of marginalization, $X^{2}(66)=2.66$, though our sample was primarily female. Given our sample sizes, we examined ethnicity as binary variable of White $(n=49)$ versus non-White $(n=29)$. As expected, ethnic minority participants differed from majority participants, $X^{2}(2)=6.72, p<.05, v=.32$. White participants were over-represented in the non-marginalized group $(A S R=2.6)$, and non-White participants were over-represented in the marginalized group $(A S R=2.0)$. The middle group showed the non-White group slightly over-represented $(A S R=1.3)$. Is elaborating an alternative narrative associated with greater identity processes than elaborating a master narrative? 
Elaborating the alternative narrative was associated with more positive meaning, $r(77)=$ $.31, p<.01$. Elaboration of the master narrative was marginally associated with more positive meaning, $r(77)=.22, p=.05$. There were no associations with negative meaning, and there were no demographic differences for master or alternative elaboration, or meaning.

Can the alternative narrative be constructed without referencing the master narrative?

Elaborating the master narrative was correlated with elaborating the alternative narrative, $r(77)=.54, p .001$, which could be a marker of generalized narrative elaboration. However, we were more interested in whether there were differences in the frequencies of people who elaborated on one and not the other. Thirty-five percent of the participants elaborated the master narrative (score $>2$ ), with less elaboration of the alternative narrative (score $<3$ ). In contrast, $18 \%$ elaborated the alternative narrative (score $>2$ ), with less elaboration on the master narrative (score $<3$ ). Thus, consistent with our hypothesis, it is less common to discuss the alternative narrative without elaborating the master narrative than elaborating the master narrative without elaborating the alternative narrative.

Overall, those who were ethnic minorities were more likely to report experiences of marginalization, as expected. Also as expected, those who elaborated an alternative narrative reported more positive meaning, which was also the case with master narrative elaboration. Finally, and as expected, it was less likely to elaborate the alternative narrative without references the master narrative, which may facilitate its' rigid staying power. In Study 2, we used the same survey, but our participants were over-sampled for ethnic and sexual minority statuses, we obtained a more equal ratio of males and females, we obtained our participants from a larger public institution, and we also collected a larger sample.

\section{Study 2: Methods}


Study 2 was conducted in exactly the same way, and with the same materials, as Study 1, with the exception of one survey that was not used in the present analyses.

\section{Procedure}

Participants were recruited from undergraduate psychology courses, which serve a variety of students for general education requirements, as well as those who are, or intend to be, psychology majors. Participants completed the entire survey on qualtrics in a room alone. Surveys included assessments of personality, well-being, and identity statuses (not examined here). Participants were given course credit for participation, which took an average of 1 hour.

\section{Participants}

Participants were 271 undergraduate students at a mid-sized public university in the western United States. Fifty-five percent were females $(n=145), 42 \%$ were males $(n=115)$, and $4 \%$ declined to answer or stated "other" $(n=11) .58 \%$ were White $(n=157), 15 \%$ Asian $(n$ $=41), 14 \%$ were Mixed $(n=39), 4 \%$ Latino $((n=10), 2 \%$ Black $(n=6), 1 \%$ were Native American $(n=2)$, and $2 \%$ Other $(n=5)$. Seventy-two percent were heterosexual $(n=196), 12 \%$ were bisexual $(n=12), 4 \%$ were homosexual $(n=4)$, and $8 \%$ listed other $(n=22)$. Mean age was $20.51(S D=2.09$, range $=18-29)$.

\section{Materials}

Materials were identical to those in Study 1.

\section{Narrative Coding}

The third author trained with the first author to establish reliability with the coders from Study 1 on the entire dataset of narratives from Study 1. The third author subsequently coded the data for Study 2 (and for Study 3). Reliability was acceptable for master narrative elaboration $(i c c=.85)$, alternative narrative elaboration $(i c c=.70)$, negative meaning $(i c c=.74)$, and 
positive meaning $(i c c=.76)$. As reported in Study 1 the marginalization code was developed by the first and third author using the first dataset (kappa $=.77)$.

\section{Study 2: Results}

Analyses were conducted in the same way as Study 1. Descriptives of the main variables can be found in Table 2 .

Are Master Narrative Deviations more elaborated for those who are in marginalized positions in society?

In this sample, $3 \%(n=8)$ of participants did not answer the question, and $4 \%(n=11)$ reported that they did not have such a deviation experience. These participants were $60 \%$ male, $93 \%$ heterosexual, and $60 \%$ White. Of those who reported codeable narratives, $50 \%$ participants reported narratives that were not about structural inequality, 33\% received a code of one, and $17 \%$ reported a deviation narrative about being in a position of structural inequality.

A one-way ANOVA examining the relation between the type of marginalization expressed in the narrative and meaning and master and alternative elaboration showed an effect on master narrative elaboration, $F(2,249)=4.84$, partial $\eta^{2}=.04, p<.01$, and marginally for alternative narrative elaboration, $F(2,249)=2.68$, partial $\eta^{2}=.02, p<.10$. Post-hoc Tukey's tests showed that those whose narratives were about being in the most marginalized position (mean $=2.53)$, had higher scores for master narrative elaboration than those in the middle (mean $=2.08$ ) or a lowest group (mean $=2.07$ ) (there was a similar trend for alternative narrative development, but was not significant in post-hoc tests). In terms of meaning, there was no effect for positive meaning $(F=1.88)$, but there was an effect for negative meaning, $F(2,249)=3.49$, partial $\eta^{2}=.03, p<.05$. Post-hoc Tukey's tests showed that those whose narratives were about begin in the most marginalized positions (mean $=1.88)$ reported higher negative meaning than 
those who were least marginalized (mean $=1.48$ ); the group in the middle did not differ from either of the other groups.

In terms of demographics, there were gender differences in marginalization, $X^{2}(2)=$ $8.46, p<.05, v=.18$. Males were overrepresented in the non-marginalized group $(A S R=2.7)$, less represented in middle group $(A S R=-2.6)$, and the most marginalized group $(A S R=-4)$. There was also an effect of ethnicity, $X^{2}(2)=14.57, p<.001, v=.24$. Ethnic minority participants were under-represented in the middle group $(A S R=-2.7)$, and over-represented in the group whose narratives were about experiences of structural marginalization $(A S R=3.4)$; there were no differences for codes of zero. Finally, there were also effects in terms of sexual orientation, $X^{2}(2)=31.81, p<.001, v=.35$. Heterosexual participants were overrepresented in group whose narratives were not about structural marginalization $(A S R=5.3)$, and underrepresented on in the middle group $(A S R=-2.2)$, and for $2(A S R=-4.2)$. Is elaborating an alternative narrative associated with greater identity processes than elaborating a master narrative?

Elaborating the alternative narrative was associated with both positive, $r(252)=.22, p<$ .001 , and negative meaning, $r(252)=.21, p<.01$. There were no associations between master narrative elaboration and meaning (all $p$ 's $>.05$, all $r$ 's $<.05$ ).

There were also demographic differences in these narrative processes. First, there were gender differences in master narrative elaboration, $t(243)=-2.02, p<.05$, and negative meaning, $t(243)=-2.33, p<.05$. Females (mean $=2.26)$ had greater elaboration of master narratives than males (mean $=2.04)$, as well as greater negative meaning $($ mean $=1.76)$ compared to males $($ mean $=1.46)$. Second, examining ethnicity with the four largest groups (White, Asian, Latino, and Mixed), there were no mean level differences. Using the binary ethnicity variable, there were 
trends for positive meaning, $t(243)=-1.92, p=.05$, and negative meaning, $t(243)=1.69, p=.09$. White participants tended to have more positive meaning $($ mean $=1.14)$ than non-White participants $($ mean $=1.07)$, and non-White participants tended to have more negative meaning $($ mean $=1.12)$ than White participants $($ mean $=.90)$. Third, there was a difference for positive meaning, $t(244)=2.36 p<.05$, and a trend for master narrative elaboration, $t(243)=-1.76, p=$ .08 for sexuality. Heterosexual participants had greater positive meaning (mean $=2.05)$ than nonheterosexual participants $($ mean $=1.67)$, and heterosexual participants $($ mean $=2.10)$ tended to have less elaboration of the master narrative than non-heterosexual participants (mean $=2.33$ ). Given our sample size, we take the marginal results with caution.

Can the alternative narrative be constructed without referencing the master narrative?

Elaboration of the master narrative was associated with elaborating an alternative narrative, $r(252)=.33, p .001$. As in Study 1, we examined the frequencies of those who elaborated the master narrative with less reference to the alternative narrative and vice-versa. Eighty participants elaborated the master narrative (score $>2$ ), with less elaboration of the alternative narrative $($ score $<3)$. One participant elaborated the alternative narrative (score $>2$ ), with little elaboration of the master narrative (score $<3$ ). Thus, consistent with Study 1, it is far less common to discuss the alternative narrative without reference to the master narrative. But one can elaborate the master narrative without elaborating the alternative narrative.

In sum, as in Study 1, we found that the minority of participants reported a narrative about structural marginalization. However, as expected, those that did report such narratives were more likely to be female, or ethnic or sexual minorities. We also saw that those in the most marginalized position reported more elaboration of the master narrative and more negative meaning, the latter of which was also the case for women, and ethnic and sexual minorities. As 
expected, elaborating the alternative narrative was associated with both positive and negative meaning, and elaborating the alternative narrative without referencing the master narrative was less common than the reverse. In Study 3 we turn to a mid-life sample, which allows us to begin to consider issues of developmental stage, though we did not have apriori hypotheses given the lack of data on these topics in adulthood.

\section{Study 3: Methods}

Participants for this study are a part of The Foley Longitudinal Study of Adulthood (FLSA), a 10-year longitudinal study of psychological and social development in late midlife and beyond. Participants were recruited by a consultant, Metro Chicago Information Center, using flyers, bulletin board postings, and paid advertisements. Materials were displayed at community centers, public libraries, local newspapers, religious institutions, grocery stores, etc. The final sample is made up of relatively healthy mid-life adults who completed a wide battery of psychological, social, and health assessments every year of the study. During Wave 7 participants completed an online survey via qualtrics, and a 15-20 minute phone interview. The master narrative deviation prompt was given as part of the on-line survey. Participants were compensated $\$ 75$ for the survey, and given a $\$ 10$ Target gift card for the interview.

Participants. At Wave 7163 participants participated. Fifty-eight percent were females $(n=105), 50 \%$ were White $(n=90), 39 \%$ Black $(n=70), 2 \%(n=3)$ were interracial or other. Mean age was $61.58(S D=1.04$, range $=59-64)$. Thirty-eight percent $(n=68)$ completed postgraduate work, $22 \%(n=39)$ completed some college or college, $5 \%(n=9)$ completed high school, and 4\% $(n=8)$ responded with other. Forty-three percent were married or partnered $(n=$ $77), 18 \%$ divorced $(n=33), 6 \%$ widowed $(n=11)$, and 14\% single $(n=25)$. Twenty-six percent 
reported income above $\$ 150,000(n=47), 24 \%$ reported income between $\$ 75,000$ - $\$ 149,999$, and $41 \%$ reported income below $\$ 75,000$. Percentages do not all equal 100 due to missing data. Narrative Coding

Coding for these narratives was described in the methods section of Study 2.

\section{Study 3: Results}

Analyses were conducted in the same way as Study 1. Descriptives of the main variables can be found in Table 2 .

Are Master Narrative Deviations more elaborated for those who are in marginalized positions in society?

Twenty-nine people (18\%) participated in the study and did not answer the question, and 36 participants $(27 \%)$ of those who answered the prompt reported that they had not deviated (66\% female, and $57 \%$ White). The rest of the analyses focus on those who produced codeable data $(n=83)$. Fifty-one percent of participants reported deviation narratives that were not about structural inequality, $39 \%$ were in the middle, and $11 \%$ reported a narrative in which the deviation put them in a position of structural inequality.

There were effects of marginalization for the elaboration of the master narrative, $F(2,80)$ $=5.22, p<.01$, and marginally so for elaboration of the alternative narrative, $F(2,80)=2.12, p<$ .10. Post-hoc Tukey's tests showed that those whose narratives were about being in the most marginalized position reported greater elaboration of the master narrative (mean $=2.67)$ than those whose narratives were about being in the last marginalized position (mean =1.69); the middle group did not differ from either of the other groups. There was a similar trend for alternative narrative development, but was not significant in post-hoc tests. There were no effects for positive $(F=.58)$, or negative $(F=1.29)$ meaning. 
In terms of demographics, there were no gender differences for marginalization $\left(X^{2}=\right.$ 1.63). There was an effect of ethnicity, examining African-American v. White as the two largest groups, $X^{2}(2)=6.47, p<.05, v=.28$. White participants were somewhat overrepresented in the group whose narratives were not about marginalization related to structural inequality $(A S R=$ $.6)$, and the mid-level group $(A S R=1)$, and underrepresented in the group whose narratives were about being in positions of structural inequality $(A S R=-2.5)$. There were no effects of income $(F=1.57)$, education $(F=.00)$ or marital status $\left(X^{2}=5.86\right)$ for marginalization.

Is elaborating an alternative narrative associated with greater identity processes than elaborating a master narrative?

Elaboration of the alternative narrative was associated with positive meaning, $r(83)=.22$, $p<.05$; there were no relations with negative meaning, and there were no associations with master narrative elaboration and meaning.

In terms of demographics, there were gender differences in alternative narrative elaboration, $t(81)=-1.78, p=.08$, with females showing greater alternative narrative development $($ mean $=2.85)$ than males $($ mean $=2.45)$. There were gender differences in positive meaning, $t(81)=-4.06, p<.001$, such that females $($ mean $=1.98)$ had more positive meaning than males $($ mean $=1.05)$. Finally, those with more education were more likely to elaborate the master narrative, $r(83)=.28, p<.05$. There were no effects of income or ethnicity. Can the alternative narrative be constructed without referencing the master narrative?

As in Studies 1 and 2, elaboration of master and alternative narratives were associated, $r(83)=.46, p .001$. Four people elaborated the master narrative (score $>2)$, and not the alternative narrative $($ score $<3$ ). None elaborated the alternative narrative (above $>2$ ), with little elaboration of the master narrative $($ score $<3)$. 


\section{Summary of Quantitative Results: Studies 1 - 3}

First, most participants did not report experiences about structural inequality, but those who did were more likely to be ethnic minorities (Studies 1, 2, 3). The only study that included sexuality (Study 2) showed that being a sexual minority was associated with experiences of greater marginalization. Gender differences in marginalization were only significant in Study 2, with women more likely to report experiences of marginalization, though we were compromised by sample size in Study 1. Finally, those whose narratives were about being in more marginalized positions were more likely to elaborate the master narrative (Studies 1, 2, 3). Second, alternative narrative elaboration was associated with more positive meaning across all three studies. Finally, across all three studies participants were less likely to elaborate the alternative narrative without referencing the master narrative. They were more likely to reference the master narrative without referencing the alternative narrative. Thus, we found important consistency across three samples diverse in age, demographics, and location. These confirm several proposals concerning the role of master narratives and structural inequality, alternative narrative development and identity work, and potential explanations for the rigidity of master narratives. What we do not know from these three studies, however, is how these deviations are narratively constructed, and what they look like. For that, we turn to Study 4.

\section{Study 4: Qualitative Analysis of the Content of Deviation Narratives}

Our aim in this study was to better understand the content of narratives about master narrative deviations. Recent calls for the attention to the content of identity development (e.g., Galliher et al., in press; McLean et al., 2014; McLean et al., 2016; Syed, in press) have argued that understanding what is developing is necessary for a full understanding of how a phenomenon develops. Further, examining content necessitates an analysis of the cultural 
contexts of identity development, and narrative provides an optimal measurement because of the descriptive and qualitative nature of the assessment (Galliher et al., in press; McLean \& Syed, 2015; see also Gergen, Josselson, \& Freeman, 2015).

Two of the emphases in on which we have focused here are on the role of structural inequality, and the importance of constructing alternative narratives for those who deviate. Thus, we selected those whose narratives were about being in a position of structural inequality, and who elaborated the alternative narrative. Our aim was to understand what the narratives revealed about the experience of marginalization and the construction of alternative narratives in order to build theory and further lines of inquiry within this framework.

\section{Study 4: Method}

\section{Participants}

For this study, we selected participants from Studies 1 - 3 whose narratives were about being in the most marginalized positions ( $\operatorname{code}=2$ ), and who had also elaborated the alternative narrative at the higher end of our scale (code $>2)$. This resulted in a sample size of 48 cases $(n=$ 7 (9\%) from Study 1; $n=36(13 \%)$ from Study $2 ; n=5(3 \%)$ from Study 3.

\section{Qualitative Methodology}

Our framework for analyzing these data comes from a thematic analysis approach (Braun \& Clarke, 2006; see also Wertz, Charmaz, McMullen, Josselson, Anderson, \& McSpadden, 2011). We chose this framework to see what themes emerged that might guide new lines of inquiry, and to add to the theoretical knowledge base concerning master narratives. Indeed, the aim of this kind of analysis is to construct categories from the data that can guide, or inform, future lines of research. To be clear, we did not, nor is the intention of this kind of method, to engage as if there are no apriori ideas about the data. Indeed, we have already applied theory, 
codes, and questions to these data. The goal is rather to examine the data from a different lens, without a rigid theoretical guide, and to question apriori assumptions and interpretations. Thus, we were not looking to confirm what we had already found in Studies 1-3, but rather to see what more we could learn from analyzing these narratives with a 'fresh' look, and to see what we might be missing in applying our relatively standard codes and methods.

The first author, along with a group of graduate and undergraduate students read and discussed the narratives, with the guiding question of 'what stands out?' Once a saturation point was reached (no new themes were discovered), the first author re-read all narratives, examining each theme on its own to discover how that theme emerged in each of the narratives. After that process, three themes were chosen to report here. Consistent with our study aims, we chose to focus on the themes that offer something new to the theory to push further work.

\section{Theme 1: The Multiplicity of Deviations}

The master narrative framework was written in the language of deviation, emphasis on the singular. Clearly, with knowledge of the human condition as well as theories of intersectionality (e.g., Cole, 2009), we know that individuals can deviate in many ways. And one of the most common themes in our analyses was about the multiplicity of deviations. Although this is not inconsistent with the original framework, it was not emphasized, and is an important empirical reminder of the reality of individuals' experiences.

We saw two ways of deviating in multiple ways. First, some individuals deviated from multiple master narratives. For example, being a lesbian and not wanting to have children is a deviation from two different life course master narratives - one about sexuality and one about childrearing. Although they may share some connections (e.g., greater challenges of childbearing), they are deviations about two different master narratives. 
Second, some individuals deviated from the alternative narrative, which is already a deviation of the master narrative. That is one can deviate on top of a deviation, or what we call intersectional deviation. The following are deviations from an alternative narrative, in which one is already deviating due to one's marginalized status as an ethnic minority, but then does not conform to the life course narrative for that sub-group, in this case being Asian-American.

Growing up in a 50\% Asian community (in the United States), Asian-American and Chinese-American stereotypes have often dictated my life -- from what I should eat and wear, to which subjects I should like in school, to how I should behave and how I should view my career trajectory. My family and I, though, don't quite fit the mold. At home, I eat my meals -- which are not always Chinese food -- with a fork, not chopsticks. My clothes are capricious and unusual, not quiet and reserved like those of the stereotypical Asian female. I don't particularly enjoy nor excel in the stereotypically "Asian" subjects, math and science. I don't speak Chinese, a flag that other Asian-Americans often take to mean I'm far too "Americanized" to be considered Asian. And I don't want to follow the stereotypical life path, as I am equally uninterested in medical school, law school, and business school.

I was raised as a typical Asian girl, reserved, shy and innocent... During past 4 years in college, I became knowledgeable on issues that I was unaware of in high school... One time, my mom was so shocked about how "provocative" I have become, she did know what to say. Don't get me wrong. I love my parents and they still love me even though I have not turned out to be the type of woman they thought I will become. I am more openminded, more passionate and more feisty. Whenever I tell my parents about my new identity that I have found for myself, and whenever I see them in shock or in awe, I feel powerful. I feel that I have become more than what I thought I was capable of.

In these two examples, we see individuals whose life courses already deviate from the majority by the objective status of their ethnicity. But then we see that they do not follow the alternative narrative for this sub-group, resulting in an intersectional-deviation. Indeed, these two participants are following an "Americanized" master narrative, so the deviation from the alternative narrative returns them to aligning with the master narrative (more on this in Theme 3 below). However, given the immutable, and visible, characteristic of ethnicity, this alignment with the American master narrative is not clearly accepted by others. This highlights the complexity of ascribed and visible deviations, where one's feelings and identity constructions are 
in some ways partly 'owned' by the expectations of others, an important constraint of master narratives (McLean, 2015; see also Galliher et al., in press). Finally, these participants are reifying stereotypes, which may help to perpetuate them (see Rogers \& Way, 2016), and the consequent narratives in which they are embedded, a possible explanation for the rigidity of narratives.

These cases also raise another important issue concerning the definition of deviation - for these two participants the subjective perception is not about deviating because of being Asian, but about deviating because of not following the 'Asian Lifecourse Narrative' - an alternative narrative that appears so established and accepted that it has become a master narrative, implicitly assumed from the start of the narratives. Thus, the intersectional deviation label in these cases is what we, as researchers, have imposed, a decision we made due to the objective structural and cultural sanctions imposed on ethnic minorities in the US, and given the emphasis on power and inequality in the master narrative framework (McLean \& Syed, 2015). However, these cases may be meaningfully different from those in which the intersectional deviation is consciously felt at all levels, as in the following:

As a white male from a well-off, liberal, Jewish family I've always been expected to excel in everything, attend a top college, earn a graduate degree from a recognized school, and get married to a charming but not overly attractive girl to provide my parents with nice, well-off, grandchildren. I guess my being gay would be a divergence from those expectations...I've also diverged from what's considered normal and expected of a young gay male. I'm not at all feminine like many of the caricatures on TV series, etc., and don't fulfill the "gay best friend" role that a number of straight women have asked me to fulfill. So, in that sense, I've diverged from their expectations as well. It has upset me a fair bit over the last 5 years, and makes me feel as if I'm floating in a void, fulfilling nobody's expectations but my own.

This person is deviating from the (heterosexual) life course master narrative in terms of partnership and potentially childrearing. However, he does not fit the well-established alternative narrative for the gay life course either, deviating from the homosexual alternative 
narrative. Without a master or alternative narrative, this individual is left without a clear story with which to align his personal narrative, and he is left alone (see Theme 2 below). Deviating from the alternative narrative may be particularly challenging, because there is no a story for the alternative narrative to the alternative narrative. Another way of putting this is that there may not be a story format for those with multiple deviations; perhaps the more idiosyncratic the identity, the less of a cultural framework there is from which to draw, which can result in a feeling of invisibility, or 'floating' as this participant puts it (Purdie-Vaughns \& Eibach, 2008).

\section{Theme 2: Deviations as Lack of Belonging/Need to Belong}

McLean and Syed (2015) emphasized the importance of power and structural inequality in their recent proposal about the negotiation between personal and master narratives. From their perspective, this emphasis on power provides a new and critical lens for to the mainstream study of identity development, particularly in relation to the barriers that some individuals might face in developing an identity. What we learned in this analysis, however, is that one way that those in positions of structural inequality, and with less power, experience this location is through the loss of connection to others. In other words, the experience of structural marginalization may be tightly linked to social marginalization; not fitting in with the master narrative is about a loss of power, as well as a loss of belonging. This suggests that the work of constructing an alternative narrative is not a solitary activity - one must find another group with which to belong.

The most common way that this theme was raised was in the explicit, often visceral, references to these feelings of alienation, as is seen in the excerpts below:

That made me feel like I don't fit in anywhere and there is no place for my identity...I think many of my identities, which carry stories, have been dismissed many times by various communities which has made sharing my stories hard.

I have never had a true family or felt like I belonged with any one group of people. I am called a "free bird" by many... but some don't know how much that title stings sometimes. 
I am 26 and I still struggle with identity and sense of self. I am very confused about who I am as a person.

No one could relate to me, and no one tried...It was an ongoing battle, and I don't think I ever won.

Holding conversations with people can be difficult. I sometimes feel angry when I think about these things just simply because I don't really "fit in" with either cultures. I don't fit with the "American" culture, but yet I don't fit with my family's culture either. It's a strange situation to be in and a lot of people don't understand...I have a tendency to get upset, angry, irritable, so I withdraw and go do things on my own.

I don't really fit in any categorical box or group; I'm a floater. I'd say no one has ever asked me about this or heard me speak about my hardships and experiences.

I feel distant from others who have had an ideal childhood. They have bonds and memories that I don't have.

The full narratives from which these excerpts are derived have the sense of feeling unresolved, as if they are not fully storied. However, one resolution to the story of deviation may be to find a new group, which comes with an alternative narrative. For example:

It was jaw dropping, because all this time I felt like I wasn't normal, I didn't fit into the majority, but there were actually other people who felt the same way and I wasn't alone. I never realized how alone I had felt until I realized I wasn't.

Thus, the location of marginalization is intimately connected to issues of relationships and social connection. These narratives illustrate the idea that we cannot be fully defined without a group. There is no shortage of theories concerning the relation between identity development and connection with others although this is often examined in dyads (e.g., Allen, Hauser, Bell, \& O’Connor, 1994; Grotevant \& Cooper, 1985), but here we see the role that a larger group and the connection to that group plays in identity development. This dovetails nicely with the robust research on ethnic identity development (see Phinney, 1990; Syed \& Azmitia, 2008), ${ }^{1}$ which focuses on connection to one's ethnic group as an important component of a healthy identity. What our data add to the discussion is a focus on deviation from the norm, 
as well as the nuances of belonging when there are multiple potential narratives, aligned with various groups (i.e., master and alternative).

\section{Theme 3: Using other Master Narratives to Manage Deviations}

Once one has deviated from the master narrative the question becomes how does one construct an acceptable alternative? One approach to this issue is to employ other master narratives to structure the deviation, as we saw the two Asian participants doing in their intersectional deviations above. Most common in the present datasets were individuals using the structural master narrative of redemption. This structure frames an event as moving from negative to positive; thus, the negative is redeemed, and the narrative is resolved (McAdams, 2006). Redemption and positive narrative resolution have been found to be critically important to psychological well-being (see Adler, Lodi-Smith, Philippe, \& Houle, 2016 for a review), and also exemplify a particularly American master narrative (McAdams, 2006). Following are some excerpts that illustrate this theme.

Whenever I tell my parents about my new identity that I have found for myself, and whenever I see them in shock or in awe, I feel powerful. I feel that I have become more than what I thought I was capable of.

There are many times I've wished I fit into the norm, although i recognize my identities and my stories make me unique and that they're beautiful.

I am also okay with my past because it has helped mold me into the person I am today.

The use of the redemptive structure provides an acceptable organization for a story, even if the content of the story is less acceptable. In other words, deviation in content is buffered by conformity with structure of telling the story.

As we read and re-read the narratives of redemption, we discovered another link to McAdams' work on redemption - the connection to generativity. McAdams has found that those with more redemptive life stories also consistently score higher on measures of generativity (e.g., 
McAdams \& Guo, 2015). McAdams has argued that telling redemptive stories is one way to sustain one's generative instincts and behaviors. Indeed, being generative - giving back to future generations - takes effort, and the belief in good coming from bad may serve as an ideology that supports continuing such challenging work, a theme well-articulated in the narratives below:

I grew up in an urban community and went to very populated public schools. Ifeel that society normally would think that a student from this environment would end up not going to college or may just attending a community college. Fortunately I do attend a really nice college. Growing up with the idea that I could possible not go to college just because of where I live made me feel angry. I felt like I had the right to go where ever I wanted and my background shouldn't stop me from anything. Now that I am attending a top school that I wanted to attend, I feel happy and accomplished. Being able to go to any college of my choice even though I did go to terrible public schools and did not have access to many opportunities, is important to me because it proved to me that I can do whatever I set my mind to. It also makes me feel like my experience may help another kid in my neighborhood accomplish their goals.

Over the years I've gathered the strength to overcome them [problems with mental health] (though they both still get frustrating at times), but not everyone is as lucky as I am. That's why I want to get a Psychology degree and help people!

I haven't met many other, if any guys who learned these lessons at such an age and have wholeheartedly applied them in their life as I have. I reject the stereotype of men in society, and seek to help those who struggle with their identity.

Though McAdams has focused on generativity primarily in mid-life, it may be a motivation that arises earlier for those who are burdened by oppression (see also Hammack, 2010; Syed, 2010). Those who see inequality, may be more likely to organize their identities - across development around the theme of redemption and generativity.

In sum, our qualitative analyses brought attention to issues that are consistent with, and build upon, the master narrative framework: the multiplicity of deviation, the experience of social disconnection, and the strategies used to narrate such deviations.

\section{General Discussion}


Across four studies and three samples we have used the master narrative framework to target the dynamic relation between the individual and society as identities are forged. In this initial investigation, we found that many people (62\% in Study 1, 50\% in Study 2, 51\% in Study 3) did not report experiences of structural inequality as their deviations. Yet those who were more marginalized were more likely to elaborate on what the master narrative is, and those who elaborated on an alternative narrative also reported more identity work. We also found evidence for the claim that one reason master narratives are so rigid is that they are referenced so frequently as individuals story their lives, forming a backbone to many stories, even those that are about not being a part of the master narrative. Below, we elaborate on some of the more critical and novel findings.

\section{Master and Alternative Narratives and Structural Inequality}

The Rarity of Structural Deviations. We begin by noting that the rarity of deviations is not entirely problematic, as these data are an important answer to our question about perceptions of deviation and for comparison analyses; indeed, we provided some evidence that majority groups were over-represented in the groups that did not report structural marginalization. However, we must also consider why so many did not report a deviation of structural inequality. The first plausible explanation is in our samples. Despite efforts in Studies 2 and 3 to recruit more diverse samples, it is clear that diversity of ethnicity, sexuality, and social class do not necessarily match with reported experiences of deviation. That is, those who were recruited based on their demographic characteristics that put them in a more marginalized position, did not necessarily report a narrative consistent with that. It may be that such experiences are not as central as we expected, that they are buffered by other aspects of the self, or that they are stories that are not readily shared, among other possibilities. Of course, we do not assume that these 
stories do not exist, and it is likely that they are heard somewhere, perhaps in the communities in which they are developed. Thus, alternate methods of eliciting narratives - perhaps in focus groups, or targeting activist groups - might elicit a different set of stories. That we would need to dig deeper to find such stories is an important reminder of the samples who are usually given voice (in research, and in the culture at large). Indeed, if alternative narratives were more prevalent in the broader populace, master narratives would not be so powerful. As McLean and Syed (2015) suggested, however, this is not simply a numbers game; it is a power game (see also Fivush, 2010). Those who use the master narrative are more likely to control the airwaves, so to speak - in the news and popular media, as well as in positions of political and economic power. Thus, it will take work by those with different stories to tell, as well as for those who control the stage for the airings of these stories, to broaden the available narratives that are valued and accepted for self-definition. However, we also note that examination of such stories in particular sub-groups is likely to show greater frequencies of such stories, and is an important avenue for future research.

Those who are marginalized can tell us about Master Narratives. One of the claims made by McLean and Syed (2015) is that many people are unaware of their own use of master narratives, especially those who are in the privileged position of aligning with the master narrative. Thus, one way to understand what master narratives are is to query those who deviate. We found evidence for this, as those who were in more marginalized positions elaborated more on the master narrative. For example, in the first example of intersectional deviation we saw that the master narrative of the life course includes what one should eat and wear, what subjects are acceptable to like in school, what behavior is acceptable, and what careers are acceptable. These are some of the markings of what makes a life, and a person - an identity - valued and accepted. 
Those who eat what they should, wear what they should, and obtain the right jobs might not know that they are being 'right.' Thus, if we want to define the culture, asking those who do not fit in can start to tell us what the culture actually looks like. Indeed, these results are consistent with work in the ethnic identity literature that has shown that ethnic minority individuals tend to engage in greater analyses of the structural level of race and ethnicity, as well as to personalize those analyses with their own experiences (Juan, Syed, \& Azmitia, 2016; Syed, 2010; 2013; Syed, Juan, \& Juang, 2011; see also Rogers \& Meltzoff, 2016).

However, as we discussed in the results of Study 4, we engaged in some degrees of imposition in defining master and alternative narratives. The participants positioned themselves in relation to deviation prompt - defining if they had deviated, and if so, how - allowing us to see how they represented the master narrative and what 'counts' as deviation. However, as noted in out discussion of intersectional deviation, some of our codes did not always clearly line up with the participants' ideas about how they had deviated, a decision we made due to the centrality of power and inequality in the framework, and due to the lack of awareness that many people have about how or whether they align with master narratives. This lack of awareness makes capturing master narratives challenging, but can be remedied with other methods, such as how master and alternative narratives emerge in naturalistic conversations, a very different method that elicits fewer personal stories, but that does reveal issues of conscious awareness (or lack of it) (McLean et al., 2016, Study 2).

The Importance of Multiple Deviations. These data also pointed us to consider the challenges related to multiple deviations. From an intersectionality perspective (Cole, 2009), these deviations are not additive, but unique. For example, one of our participants wrote of her multiple deviations, which included being female, Mexican, Indigenous, queer, and having a 
mental illness. At first, she listed all of these issues as separate deviations, but towards the end of her narrative she articulates that they are not isolated:

...fighting through mental illnesses has made me feel like I'm not normal because my parents say it's a "white person" thing, and even in the white community it's not fully accepted so it's hard to be okay when a part of me keeps telling me it's not real.

Though she takes only two issues here - mental illness and ethnicity - we see how difficult it is to examine any of these deviations in isolation because they are given meaning by the ways in which they collide. Further, the lack of acceptance she feels resonates the idea put forth by Purdie-Vaughns and Eibach (2008) concerning 'intersectional invisibility,' in which those with multiple sub-ordinate group identities do not align with expectations for any group with which they are associated. This example also illuminates a point others have also raised, which is the challenge of capturing and communicating the intersection of multiple (e.g., more than two) identities - empirically for scientists, and cognitively for our participants (Bowleg, 2008; McLean et al., 2015; Azmitia, Syed, \& Radmacher, 2008; Warner, 2008).

Master Narrative Airtime. Finally, one of the challenges in this line of work is that the rigidity of master narratives is clearly confining and restrictive to many, at minimum, and dangerous, at maximum, as they keep marginalized and oppressed people in a static location, sustaining structural inequality. Of course, one reason for this rigidity is the work that those in power do to maintain these structural locations, to their benefit. Another reason is the lack of power that those who are disenfranchised have to challenge these positions. Yet another reason is the comfort that comes with predicting self and others; humans have a desire, and evolutionary predisposition, to control and predict the environment, which may result in the maintenance of familiar frameworks, even those that are harmful (see also McLean, 2015; Swann, Rentfrow, \& Guin, 2003). What we have learned in these studies is that yet another reason for the rigidity of 
master narratives, rooted in the practice of telling stories rather than the cognitions of individuals, is that they are referenced and talked about $-\mathrm{a}$ lot. When people deviate, and begin to tell another story, perhaps a story that they would hope supplants the master narrative, they have to reference the master narrative in telling that other story. Thus, the norm is reified again and again as individuals seek to tell a different story (see also Rogers \& Way, 2016).

\section{Identity Development within this Framework}

It Takes Identity Work to Tell Alternative Narratives. So how do stories change if they are so intractable and there are various conscious and unconscious investments in their static nature? Some of the power may come from the individuals with different stories to tell. One of the 'burdens' of being in a marginalized position is that those individuals can also be tasked with the work of changing those structures (see Hammack, 2010); those who benefit from power are unlikely to do it. Consistent with recent work (McLean et al., 2016), these data show that those who do the work of finding and constructing alternative narratives are also doing more identity work - they are engaged in more autobiographical reasoning. This reasoning seems in part focused on finding and creating one's group, which is critical for social change (e.g., Frost, 2015; Hammack, 2010). Further, the way in which we coded alternative narrative elaboration is consistent with Hammack and Toolis' (2015) argument that resistance to the master narrative can be an agentic act that empowers individuals, perhaps to find a more resilient and positive identity. This kind of coding focuses on the subjective sense of agency, and is distinct from examining the actual barriers for marginalized groups (see McLean \& Syed, 2016). Thus, although individuals can write empowering narratives, which may be a part of cultural change, those who are in positions to support and facilitate the kind of identity work also have opportunities to promote alternative narratives and group connections. 
Alternative Narrative Construction is Social. Another lesson from these data is that the experience of marginalization is social. Finding an alternative narrative is about finding one's group - one's sub-culture (see also McLean, 2015). Indeed, studies on a broad array of topics from veterans returning to civilian life (Orazem et al., 2016), to working class college students navigating home and school lives (Azmitia, Syed, \& Radmacher, 2013) - show that the tension between in navigating various group can be a serious source of identity strain. Indeed, recent work has shown that master narratives are partly maintained via social interaction, such that the desire to connect with others trumps the desire to air challenges to the status quo (McLean et al., 2016). Thus, in thinking about the facilitation of constructing alternative narratives, a social lens is critical - these narratives are developed and maintained with others, and they define others as a part of a group to which the individual can belong.

Coping with Deviations. Our final lesson concerning the role of these deviations in identity work concerns the ways that individuals appear to cope with their deviations. The first is in the use of other master narratives to structure one's deviation. This may be quite adaptive for the individual, but does run the risk of reifying master narratives - yet another addition in the rigidity argument. The tension between individual health and cultural change is one that is not lost here (see also Hammack, 2010). Perhaps more positively for the larger group, we also saw a mechanism of coping centered on generativity. Understanding one's deviation as central to one's identity and then feeling motivation to help others in similar situations may be a strategy that serves the needs of the individual as well as others. Finally, we note that the need to cope with these various aspects of identity supports the notion that the need for integration of self is a pressing modern concern, contrary to claims of a post-modern shift towards multiplicity (McAdams, 1997; see also Syed \& McLean, 2016). 


\section{Limitations and Future Directions}

Our primary limitation concerns the university samples in Studies 1 and 2, though they do come from quite different institutions. These samples compromise a relatively privileged group of individuals, as was evident in our analyses. That is, even those who are in more marginalized positions by virtue of gender, ethnicity, or sexuality, are in a less marginalized position by virtue of their educational status. Though our effort was towards an initial understanding of majority-minority differences, expanding these questions to different groups of emerging adults will be important (see Warner, 2008 for a discussion of examining one master and emergent categories). Such a direction would also allow researchers to target specific subgroups to better understand the unique content of alternative narratives with which subgroups are negotiating. The community sample elicitation strategy in Study 3 was successful in recruiting an ethnically diverse sample of adults. Mechanisms that we have found useful for capturing nonuniversity samples include partnering with community agencies that serve underprivileged youth populations, or engaging with community or technical colleges, which house a great diversity of programs for varying groups of emerging adults (e.g., reentry, recent immigrants). Further, as mentioned earlier, examining whether deviation narratives 'match' demographic characteristics, and the meaning of matches and mis-matches may be interesting. For example, what does it mean for someone who is a sexual minority to narrate that as a deviation versus some other experience (e.g., having a parent with mental illness)? Such an analysis may tell us what components of identity are more salient to particular individuals.

Another important avenue for researchers interested in this line of work is developmental in nature. First, those who felt that they had not deviated were more likely to be in the mid-life sample (a sample with a plenty of room for perceiving deviation in terms of ethnicity, gender, 
class, and marital status). It may be that perceptions of deviation are less salient in mid-life as individuals may have a broader view on what constitutes a deviation. Indeed, the desire for uniqueness, or self-focus, may be driving the emerging adult responses to the deviation prompt (Arnett, 2000). Paradoxically, emerging adults may want both to be unique and to fit in, so the perception of deviation, and the anguish about it, may make this a particularly salient prompt. Mid-life adults should also have a more integrated identity than those still constructing an identity, which may buffer the experience of deviation. In any case, exploration of these developmental issues, both in earlier development (e.g., how do individuals become aware of these master and alternative narratives), as well as later, will be increasingly important.

We also encourage researchers to consider alternative methods for examining master and alternative narratives. For example, examining their social construction will be important (see McLean et al., 2016 for an example), given the role that social interactions seem to play in understanding both how one has deviated and in finding validation with alternative narratives. The privacy afforded by self-report measures is important for the types of stories that individuals disclosed, and a complement to such designs is to examine how such stories are (or are not) shared, and how those responses shape the stories over time. Allowing more room for nondeviation may also illuminate master narratives, or who conforms to them. However, we note that given their invisibility to many, asking about non-deviation may not be an optimal method, and employing analyses of more neutral prompts may be more fruitful (e.g., do references to master and alternative narratives appear in life story interviews, or other narrative prompts; see McLean et al., 2016).

We also note some limitations to our coding. We have discussed the variations on agency (felt v. actual), and suggest that future research may define agency in narratives in 
different ways. We chose to focus on the felt experiences of agency - whether people feel agentic in narrating their deviations, consistent with an approach taken by Hammack and Toolis (2014), which focuses attention on the individual. Another way to code such narratives would be to code 'underneath' the explicit perspective of the author, to capture barriers that may not be seen or emphasized by the author. The latter aim is consistent with the ideas put forth by McLean and Syed (2015), in which the linkage between identity and structural components of society is made more explicit. Further, our marginalization code was useful in providing some description of the content of deviations, but was not without flaws. For example, we included gender as a relatively 'immutable' aspect of identity. Although this fit with our particular sample (at least at the time of data collection; e.g., no one identified as gender fluid), this would clearly not fit other individuals or populations. At our mid-level marginalization code, some characteristics are new (being divorced), but may last (making them immutable; e.g., being a divorced woman). Thus, capturing this connection between personal experience and societal structure in varied ways will be important.

In conclusion, we hope this framework is empirically generative, building from initial (e.g., Helson et al., 1984) and more recent calls in personality psychology (Hammack; 2008; McAdams, 2006; Syed, under review) to ground the study of identity and personality development in cultural context. This particular lens brings into relief the constraints on identity development - not only in terms of ascribed identities - but also the meanings of those identities, which are also ascribed (McLean \& Syed, 2015). This approach also privileges the testimony of lived experiences as narrative evidence that play a role in social and structural change (Frost, 2015), an approach consonant in other fields focused on examining inequalities and barriers to justice (e.g., critical race theory); these testimonies are necessary to make real structural 
inequities (e.g., Solórzano \& Yosso, 2002). Finally, examining these cultural constraints and affordances, as well as the individual's role in cultural maintenance and development, pushes new ground in personality theory and research.

\section{Declaration of Conflicting Interests}

The authors declare no potential conflicts of interest with respect to the research, authorship, and/or publication of this article.

Preparation of this manuscript was supported by the following grant: Foley Center for the Study of Lives: Extension and Renewal, funded by the Foley Family Foundation of Milwaukee, WI. 


\section{References}

Adler, J. M., Lodi-Smith, J., Philippe, F. L., \& Houle, I. (2016). The incremental validity of narrative identity in predicting well-being a review of the field and recommendations for the future. Personality and Social Psychology Review, 20, 142-175.

Allen, J. P., Hauser, S. T., Bell, K. L., \& O'Connor, T. G. (1994). Longitudinal assessment of autonomy and relatedness in adolescent-family interactions as predictors of adolescent ego development and self-esteem. Child Development, 65, 179-194.

Arnett, J. J. (2000). Emerging adulthood: A theory of development from the late teens through the twenties. American Psychologist, 55, 469-480.

Arenett J. J. (in press). Life Stage Concepts across History and Cultures: Proposal for a New Field on Indigenous Life Stages. Human Development.

Azmitia, M., Syed, M., \& Radmacher, K. (2008). On the intersection of personal and social identities: Introduction and evidence from a longitudinal study of emerging adults. In M. Azmitia, M. Syed, \& K. Radmacher (Eds.), The intersections of personal and social identities. New Directions for Child and Adolescent Development, 120, 1-16.

Azmitia, M., Syed, M., \& Radmacher, K. (2013). Finding your niche: Identity and emotional support in emerging adults' adjustment to the transition to college. Journal of Research on Adolescence, 23, 744-761.

Benet-Martínez, V. (2012). Multiculturalism: Cultural, personality, and social processes. In K. Deaux \& M. Snyder (Eds.), Oxford handbook of personality and social psychology (pp. 623- 648). Oxford University Press.

Berntsen, D., \& Rubin, D. C. (2004). Cultural life scripts structure recall from autobiographical memory. Memory \& Cognition, 32, 427-442. 
Bowleg, L. (2008). When Black+ lesbian+ woman $\neq$ Black lesbian woman: The methodological challenges of qualitative and quantitative intersectionality research. Sex Roles, 59, 312-325.

Braun, V., \& Clarke, V. (2006). Using thematic analysis in psychology. Qualitative Research in Psychology, 3(2), 77- 101.

Bronfenbrenner, U. (1979). The ecology of human development. MA: Harvard University Press.

Cole, E. R. (2009). Intersectionality and research in psychology. American Psychologist, 64, 170-180.

Crocetti, E., \& Meeus, W. (2015). The identity statuses: Strengths of a person-centered approach. In K.C. McLean \& M. Syed (Eds.), The Oxford handbook of identity development (pp. 97-114). New York: Oxford University Press.

Erikson, E.H. (1959) Identity and the life cycle. New York: International University Press.

Erikson, E. H. (1968). Identity, youth, and crisis. New York: W.W. Norton.

Fivush, R. (2010). Speaking silence: The social construction of silence in autobiographical and cultural narratives. Memory, $18(2), 88-98$.

Frost, D. M. (2015). Narrative approaches within a social psychology of social justice: The potential utility of narrative evidence. In P. L. Hammack (Ed.), The Oxford Handbook of Social Psychology and Social Justice. New York: Oxford.

Galliher, R., McLean, K. C., Syed, M. (in press). An Integrated Model for Studying Identity Content in Context. Developmental Psychology.

Gergen, K. J., Josselson, R., \& Freeman, M. (2015). The promises of qualitative inquiry. American Psychologist, 70, 1 - 9.

Grotevant, H. D., \& Cooper, C. R. (1985). Patterns of interaction in family relationships and the development of identity exploration in adolescence. Child Development, 56, 415-428. 
Habermas, T. (2007). How to tell a life: The development of the cultural concept of biography. Journal of Cognition and Development, 8, 1-31.

Habermas, T., \& Bluck, S. (2000). Getting a life: The emergence of the life story in adolescence. Psychological Bulletin, 126, 748-769.

Habermas, T., \& Köber, C. (2015). Autobiographical reasoning in life narratives buffers the effect of biographical disruptions on the sense of self-continuity. Memory, 23, 664-674.

Habermas, T., \& Reese, E. (2015). Getting a life takes time: The development of the life story in adolescence, its precursors and consequences. Human Development, 58, 172-201.

Hammack, P. L. (2008). Narrative and the cultural psychology of identity. Personality and Social Psychology Review, 12, 222-247.

Hammack, P. L. (2011). Narrative and the politics of identity: The cultural psychology of Israeli and Palestinian youth. Oxford University Press.

Hart, H. M., McAdams, D. P., Hirsch, B. J., \& Bauer, J. J. (2001). Generativity and social involvement among African Americans and White adults. Journal of Research in Personality, 35, 208-230.

Harter, S., \& Monsour, A. (1992). Development analysis of conflict caused by opposing attributes in the adolescent self-portrait. Developmental Psychology, 28, 251-260.

Helson, R., Mitchell, V., \& Moane, G. (1984). Personality and patterns of adherence and nonadherence to the social clock. Journal of Personality and Social Psychology, 46, 1079-1096.

Jennings, L. E., Pasupathi, M., \& McLean, K. C. (2014). "Intricate lettings out and lettings in": Listener scaffolding of narrative identity in newly dating romantic partners. Self and Identity, 13, 214-230. 
Juan, M. J. D., Syed, M., \& Azmitia, M. (2016). Intersectionality of race/ethnicity and gender among women of color and white women. Identity, 16, 225-238.

Marcia, J. E. (1966). Development and validation of ego-identity status. Journal of Personality and Social Psychology, 3, 551-558.

McAdams, D. P. (1997). The case for unity in the (post)modern self. In R. Ashmore \& L. Jussim (Eds.), Self and Identity (pp. 46 - 79). New York: Oxford University Press.

McAdams, D. P. (2006). The redemptive self: Stories Americans live by. New York: Oxford.

McAdams, D. P. (2015). The art and science of personality development. New York: Guilford.

McAdams, D. P., \& Guo, J. (2015). Narrating the generative life. Psychological Science, 26, 475-483.

McAdams, D. P., \& Olson, B. D. (2010). Personality development: Continuity and change over the life course. Annual Review of Psychology, 61, 517-542.

McCrae, R. R., \& Costa, P. T. (1997). Personality trait structure as a human universal. American Psychologist, 52, 509-516.

McLean, K. C. (2015). The co-authored self: Family stories and the construction of personal identity. New York: Oxford University Press.

McLean, K. C., \& Jennings, L. E. (2012). Teens telling tales: How maternal and peer audiences support narrative identity development. Journal of Adolescence, 35, 1455-1469.

McLean, K. C., Shucard, H., \& Syed, M. (2016). Applying the Master Narrative Framework to Gender Identity Development in Emerging Adulthood. Emerging Adulthood, 1-13.

McLean, K. C., \& Syed, M. (Eds.). (2014). The Oxford Handbook of Identity Development. New York: Oxford University Press. 
McLean, K. C., \& Syed, M. (2015). Personal, master, and alternative narratives: An integrative framework for understanding identity development in context. Human Development, 58, 318-349.

McLean, K. C., Syed, M., Yoder, A., \& Greenhoot, A. F. (2014). Identity integration: The importance of domain content in linking narrative and status approaches to emerging adult identity development. Journal of Research on Adolescence, 26, 61-76.

Neugarten, B. L. (1974). Age groups in American society and the rise of the young-old. The Annals of the American Academy of Political and Social Science, 415, 187-198.

Orazem, R. J., Frazier, P. A., Schnurr, P. P., Oleson, H. E., Carlson, K. F., Litz, B. T., \& Sayer, N. A. (2016). Identity adjustment among Afghanistan and Iraq War veterans with reintegration difficulty. Psychological Trauma: Theory, Research, Practice, and Policy.

Pasupathi, M., \& Hoyt, T. (2009). The development of narrative identity in late adolescence and emergent adulthood: The continued importance of listeners. Developmental Psychology, 45, 558-574.

Pasupathi, M., Mansour, E., \& Brubaker, J. R. (2007). Developing a life story: Constructing relations between self and experience in autobiographical narratives. Human Development, 50, 85-110.

Phinney, J. S. (1990). Ethnic identity in adolescents and adults: A review of research. Psychological Bulletin, 108, 499-514.

Purdie-Vaughns V., \& Eibach, R. P. (2008). Intersectional invisibility: The distinctive advantages and disadvantages of multiple subordinate-group identities. Sex Roles, 59 (5), 377-391. 
Ragelienè, T. (2016). Links of adolescents' identity development and relationship with peers: A systematic literature review. Journal of the Canadian Academy of Child and Adolescent Psychiatry, 25, 97-105.

Rogers, L. O., \& Meltzoff, A. N. (2016). Is gender more important and meaningful than race? An analysis of racial and gender identity among black, white, and mixed-race children. Cultural Diversity and Ethnic Minority Psychology.

Rogers, L. O., \& Way, N. (2016). "I Have Goals to Prove All Those People Wrong and Not Fit Into Any One of Those Boxes": Paths of Resistance to Stereotypes Among Black Adolescent Males. Journal of Adolescent Research, 31, 263-298.

Rogoff, B. (2003). The cultural nature of human development. New York: Oxford.

Solórzano, D. G., \& Yosso, T. J. (2002). Critical race methodology: Counter-storytelling as an analytical framework for education research. Qualitative Inquirt, 8, 23-44.

Swann Jr., W. B., Rentfrow, P. J., \& Guinn, J. S. (2003). Self-verification: The search for coherence. In M. R. Leary \& J. P. Tangney (Eds.), (2003). Handbook of self and identity (pp. 367-383). New York, NY: Guilford Press.

Syed, M. (2010). Developing an integrated self: academic and ethnic identities among ethnically diverse college students. Developmental Psychology, 46, 1590-1604.

Syed, M. (2013). Identity exploration, identity confusion, and openness as predictors of multicultural ideology. International Journal of Intercultural Relations, 37, 491-496.

Syed, M. (under review). Advancing the Cultural Study of Personality and Identity: Models, Methods, and Outcomes. Invited commentary Current Issues in Personality Psychology.

Syed, M. (in press). Why traditional metrics may not adequately represent ethnic minority psychology. Perspectives on Psychological Science. 
Syed, M., \& Azmitia, M. (2008). A narrative approach to ethnic identity in emerging adulthood: Bringing life to the identity status model. Developmental Psychology, 44, 1012-1027.

Syed, M., Juan, M. J. D., \& Juang, L. P. (2011). Might the survey be the intervention? Participating in ethnicity-related research as a consciousness-raising experience. Identity, 11, 289-310.

Syed, M., \& McLean, K. C. (in press). Erikson's Theory of Psychosocial Development. Encyclopedia of Intellectual and Developmental Disorders. Thousand Oaks, CA: Sage.

Syed, M., \& McLean, K. C. (2016). Understanding identity integration: Theoretical, methodological, and applied issues. Journal of Adolescence, 47, 109-118.

Syed. M. \& Nelson, S.C. (2015). Guidelines for establishing reliability when coding narrative data. Emerging Adulthood, 3, 375-387.

Thorne, A. (2000). Personal memory telling and personality development. Personality and Social Psychology Review, 4(1), 45-56.

Thorne, A. (2004). Putting the person into social identity. Human Development, 253, 1-5.

Thorne, A., \& Nam, V. (2007). The life story as a community project. Human Development, 50, 119123.

Toolis, E.E., \& Hammack, P.L. (2015). The lived experience of homeless youth: A narrative approach. Qualitative Psychology, 2(1), 50-68.

Vygotsky, L. S. (1978). Mind in society: The development of higher mental process. Harvard University Press, Cambridge, Massachusetts.

Warner, L. R. (2008). A best practices guide to intersectional approaches in psychological research. Sex Roles, 59, $454-463$. 
Wertz, F. J., Charmaz, K., McMullen, L. M., Josselson, R., Anderson, R., \& McSpadden, E. (2011) Five ways of doing qualitative analyses. New York: Guilford.

Zaman, W., \& Fivush, R. (2011). When my mom was a little girl...: Gender differences in adolescents' intergenerational and personal stories. Journal of Research on Adolescence, 21, 703-716. 
The culture that I grew up in could be more old fashioned and had a hierarchy of sorts where the young listened to their elders and learned, didn't talk back, and overall did mostly what they were told. Though my mother is okay with tattoos my grandparents, who are like a second set of parents, are not. So the fact that I got a tattoo in college is something rebellious and rebellion isn't all that normal or at least spoken about in my family. To his day my grandparents do not know.

(Marginalization $=0 ;$ Master Narrative Elaboration $=4 ;$ Alternative Narrative Elaboration $=$ 2; Positive Meaning = 1; Negative Meaning = 1)

I identify currently as an asexual lesbian. I have had boyfriends and a semi-functional sex life in the past but as I am currently I have no sexual desire and I am attracted exclusively to women. For me being this feels somewhat normal but also gives me the sense that I am broken in some way, not because of my attraction to women but because I no longer feel sexual desire and it makes me feel different and like I'm a less desirable partner. I suppose the significance is that I really question what this means for my future. I fully intend on having some semblance of a nuclear family or at least have a child of my own and a source of great stress is considering how my sexuality will influence my future.

(Marginalization $=2$; Master Narrative Elaboration $=3$; Alternative Narrative Elaboration $=$ 3; Positive Meaning = 1; Negative Meaning = 4)

I did feel that in High school my story was different than most. I went to a private school while all my friends were at a bigger public school with the people I had known since kindergarten. I had fewer opportunities for fun but also felt pressured to be grateful because I was going to an expensive school. However, I became depressed because of the stress and pressure of all the work I had to do there and the lack of normal socialization. That depression became severe and changed me (in the end, it was for the better). Its significance was that when I reached college I was one of the only people among my friends who knew how to fight off emotional issues and stay stable through stressful times. I know a lot of people now who are becoming depressed or anxious for the first time in their lives and have no idea what to do or what's going on with them, so it's really affecting their ability to focus on school. That is not a struggle for me anymore, so I guess I'm grateful and I also feel sort of spiritually enlightened from the entire experience. (Marginalization =1; Master Narrative Elaboration $=2$; Alternative Narrative Elaboration $=$ 3; Positive Meaning = 3, Negative Meaning = 2)

A story that diverged from what is considered to be accepted could be when I lost my virginity. When I was 13, I made the decision to have sex with a boy who I thought was "the one." From telling people this before, $\mathrm{i}$ know a lot of people were shocked that I lost my virginity as such a young age. When it happened, I didn't think much of it, but as I get older I feel more ashamed of my decision. Mainly just because, I let myself be pressured into doing it and I was also way too young. Its significant to me, because I feel like it has affected my physical relationships with other boys. (Marginalization $=1 ;$ Master Narrative Elaboration $=3 ;$ Alternative Narrative Elaboration $=$ 3; Positive Meaning = 1; Negative Meaning = 3) 
Table 2. Narrative Ratings (mean, SD)

Study 1

Narrative Code (range)

Master Narrative (1 - 4) $2.58(.95)$

Alternative Narrative (1 - 4)2.32 (.99)

Positive Meaning $(1-4) \quad 1.72(.96)$

Negative Meaning (1 - 4) $1.40(.71)$

Marginalization $(0-2) \quad 0.53(.75)$
Study 2

$2.15(.88)$

$3.06(.75)$

$1.96(1.12)$

$1.65(1.00)$

$0.66(.75)$
Study 3

$1.92(.89)$

$2.74(.91)$

$1.73(1.01)$

$1.25(.66)$

$0.60(.68)$ 


\section{End Notes.}

${ }^{1}$ There are is also a large literature on belongingness and social identity, though it touches less on developmental context (e.g., Crocker \& Major, 1989; Tajfel \& Turner, 1986) 